\title{
Footprint mismatch in lumbar total disc arthroplasty
}

\author{
Michaela Gstoettner • Denise Heider • \\ Michael Liebensteiner $\cdot$ Christian Michael Bach
}

Published online: 3 December 2008

(C) Springer-Verlag 2008

\section{Erratum to: Eur Spine J}

\section{DOI 10.1007/s00586-008-0780-0}

The authors' family names and given names were transposed. Their names are given correctly here.

Michaela Gstoettner, Denise Heider, Michael Liebensteiner and Christian Michael Bach.

The online version of the original article can be found under doi:10.1007/s00586-008-0780-0.

M. Gstoettner · M. Liebensteiner · C. M. Bach ( $\square)$

Department of Orthopaedic Surgery,

Medical University Innsbruck, Anichstr. 35,

6020 Innsbruck, Austria

e-mail: christian.bach@i-med.ac.at

D. Heider

Orthopedic Hospital Harthausen, Dr. W. Knarrweg 1-3,

Bad Aibling, Germany 